\title{
Method for analysis and comparison in planning urban surface transport systems
}

\author{
R. Bozzo, M. Canepa, C. Carnevali, R. Genova \& G. Priano \\ CIRT, Interuniversity Research Center on Transport, \\ University of Genoa, Italy
}

\begin{abstract}
New trends in mobility demands require rapid responses on behalf of public transportation, which must provide dependable, comfortable, economically and environmentally sustainable services, with high transport capacities. In rubbertyred transportation, the only element that influences transport capacity is the length of the vehicle, as seen in the 24-meter-long buses (with traditional or hybrid drive) and trolleybuses that have appeared in recent years on the roads of several European cities also as BRT (Bus Rapid Transit). Innovations in the tramway sector have been fundamental, like interoperable tram train systems; modern rolling stocks, which are modular with lengths of up to 32 meters, quieter, and aesthetically revamped, can today be equipped by many manufacturers with wireless technology (ground-based systems or batteries), thanks to which overhead lines in areas of special architectural interest can be avoided. The LRT (Light Rail Transit) represents a rational, more economical model of the "underground" with entirely dedicated stretches of route, and with the sort of strict operating plan inherent to such systems but with much lower costs for the creation of the infrastructure. The authors of this article suggest a method of analysis to assist in these decisions by pre-emptively evaluating the current technical and economic consequences resulting from the introduction of systems of the latest design; for each case under evaluation, that is, for each line identified or hypothesized, key data regarding its technical characteristics and its transport demands must be obtained, in order to then succeed in determining the working conditions for the operation and the investment and management costs.
\end{abstract}

Keywords: urban public transport, tram-train, LRT, economic indicators, transport capacity, sustainability. 


\section{Introduction}

Now, more than ten years after the beginning of the new millennium, technological evolution has not been able to change the way people think about transportation and private automobiles are still the prevailing means of transport for going both long and short distances, as shown in Figure 1, where the country with the lowest car usage, Turkey, is still at a level of over $50 \%$.

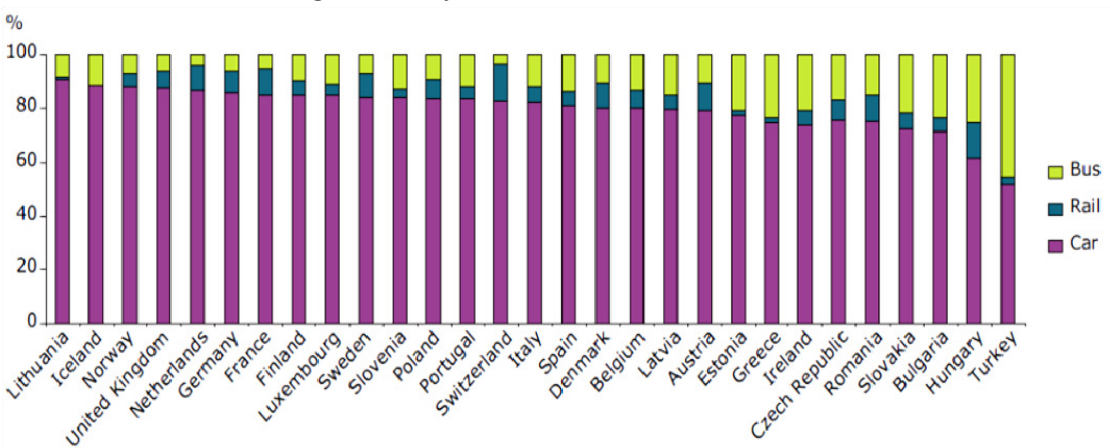

Figure 1: $\quad$ Passenger transport modal split (without sea and aviation, 2007) Source: EEA Report No 2/2010 - ISSN 1725-9177.

This occurs notwithstanding increased economic spending connected to the maintenance and insurance of vehicles and the continual price increases in fuel and parking fees. Also, notwithstanding the increasingly constricting European regulations on vehicle emissions (the Euro VI standard will be implemented 1 September 2014), the increase in the use of private vehicles has still had a negative impact, producing a rise in external costs both at an environmental level, as it increases greenhouse gases (as can be seen in Figure 2), as well as the level of liveability in cities with an increase in traffic, noise and toxic emissions for people.

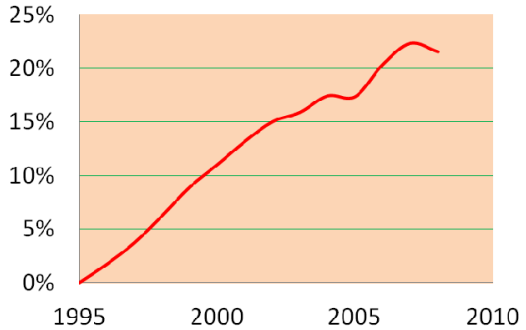

(a)

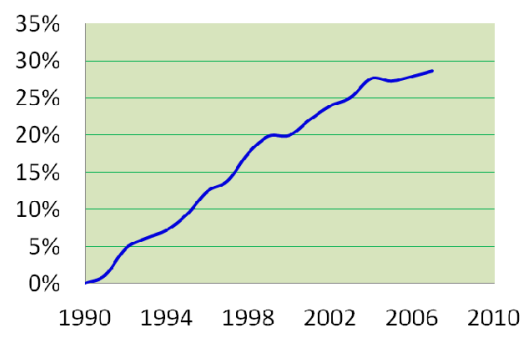

(b)

Figure 2: (a) $\%$ increase of pkm moved by car and motorbike (b) \% increase of GHG road transportation. 
Included in external costs are numerous items, the main ones are: emissions that are harmful to humans $\left(\mathrm{NO}_{\mathrm{x}}, \mathrm{PM}_{2,5-10}, \mathrm{O}_{3}, \mathrm{CO}, \mathrm{COVNM}\right)$; emissions that are harmful to the environment (greenhouse gasses $\left(\mathrm{CO}_{2}, \mathrm{CH}_{4}, \mathrm{~N}_{2} \mathrm{O}\right), \mathrm{SO}_{\mathrm{X}}$ ); traffic; accidents; noise.

More in general, using the definition of the ExternE Project (Project began in 1991 (last review 2005) financed by the DG Research within the European Joule programme. Aim of this project define external cost and impact pathway):"External cost, also known as an externality, arises when the social or economic activities of one group of persons have an impact on another group and when that impact is not fully accounted, or compensated for, by the first group". This can be represented by the equation (eqn. (1)):

$$
\mathrm{C}_{\mathrm{ext}}=\mathrm{D}-\mathrm{C}_{\mathrm{int}}
$$

where $\mathrm{C}_{\mathrm{ext}}$ is the external costs, $\mathrm{D}$ is the damage caused by generic human activities and $\mathrm{C}_{\mathrm{int}}$ the costs sustained to cover the damages of $\mathrm{D}$. Moving the private individual to public transport, and better management of the same with the adoption of innovative and ecologically sustainable technology is the only chance to reduce externalities deriving from the transport of people.

\section{Elements of quality in public transport}

The solution for the increased demand in transportation can be found in Public Administration through works aimed at making public transportation increasingly competitive compared to private means. To face this necessity, the following base parameters must be taken into consideration, in order to make the initiative a success:

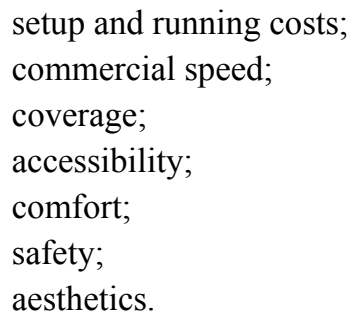

Satisfying these expectations is much easier now thanks to technology and the management models of numerous cities, which have decided to plan their sustainable development on public transport. Regarding the costs for users, the use of public transport, in most cities, is already more economical than the use of private automobiles, also because of the incentives on behalf of the State and through integrated tariff systems at a regional level. The possibility of having a single ticket which can be used on any kind of public transport makes use easier and further simplifies or integrates other services like car and bike sharing expanding the concept of door to door transport. The user must also be able to plan his trip and movements in the simplest and most immediate manner: for this, all information regarding schedules and real-time updates based on the 
location of the vehicles, must be made available. With the increased spread of smart phones, this information can be displayed not only through boards at bus stops or on displays, but also through specific apps (which can also be used to send users promotions and special offers), QR codes and NFC (Near Field Communication). In public transport, differently from private vehicles, travellers find themselves in close contact with each other: for this reason, the cleanliness, safety and hygiene of the vehicle must be guaranteed. The space dedicated to the users must be furnished with modern climate controls, and planned with ergonomic criteria to guarantee maximum comfort; the study of design also makes the vehicle more futuristic and enticing, increasing the idea that this is a reliable and modern means of transport.

\section{New perspectives for surface public transport in urban areas}

There are different systems for surface public transport in urban areas which can be divided into two categories: rubber-tyred vehicles (freely driven, or assisted) and rail systems (with guide rail). In order to make transportation effective it has to be, not only correctly sized, but integrated in an overall general plan of extended networks that allow users to travel even over long distances without transit points, or with rapid interchanges, organising the run times and using short walking distances or mechanical means (escalators and moving walkways). In choosing a transport system, three fundamental factors must be taken into consideration:

1. transport capacity;

2. setup costs for the chosen system;

3. running and maintenance costs.

In Table 1 each type of transportation is compared using transport capacity and setup costs (the latter is subdivided in infrastructure and rolling stock), while for the running costs, dependant on several factors such as numerical strength and qualified personnel, the related costs incurred for the purchase of the fuel and electricity, the costs of maintenance for the rolling stock and the fixed equipment, for each of these a personalised estimate must be made. It is possible to note, for example in rubber-tyred systems that the only element that influences transport capacity is the length of the vehicle, while the type of traction used is indifferent: traditional, hybrid or trolleybus. The situation is different for automated systems: an urban tram can carry between 2,800 and 6,000 passengers per hour per direction. At the top of transport capacity are the undergrounds, capable of transporting from 16,000 to 30,000 or more passengers/hour per direction, depending on the chosen operative model.

It must be noted that although underground railways featuring integrated automation systems have reached their maximum evolutionary and importance level (for example in Lyon, line D, Copenhagen, Nuremberg and Turin are already functioning, Brescia, Milan line 5 and Rome line $\mathrm{C}$ under construction), these have extremely high costs, around $100,000 \mathrm{k} € / \mathrm{km}$. This is why lighter 
Table 1: $\quad$ Transport capacity and infrastructure costs for different transport systems.

\begin{tabular}{|c|c|c|c|c|}
\hline Vehicle & $\begin{array}{l}\text { Passengers } \\
\text { transported } \\
\text { (1) }\end{array}$ & $\begin{array}{c}\text { Transport } \\
\text { capacity } \\
\text { (pass h dir) }^{(2)}\end{array}$ & $\begin{array}{c}\text { Vehicle } \\
\text { costs }^{(3)(4)} \\
{[k €]}\end{array}$ & $\begin{array}{c}\text { Infrastructure } \\
\text { costs } \\
(\mathrm{k} € / \mathrm{km})\end{array}$ \\
\hline Bus (12 m) & 100 & 2,000 & $150-200$ & \multirow{3}{*}{$0-100$} \\
\hline Bus (18 m) & 140 & 2,800 & $250-300$ & \\
\hline Bus (24 m) & 180 & 3,600 & $1,350-1.500$ & \\
\hline $\begin{array}{c}\text { Trolleybus } \\
\text { (12 m) }\end{array}$ & 100 & 2,000 & $600-700$ & \multirow{3}{*}{$600-800$} \\
\hline $\begin{array}{c}\text { Trolleybus } \\
(18 \mathrm{~m})\end{array}$ & 140 & 2,800 & $700-800$ & \\
\hline $\begin{array}{c}\text { Trolleybus } \\
(24 \mathrm{~m})\end{array}$ & 180 & 3,600 & $1,000-1,300$ & \\
\hline Tram & $140-300^{(5)}$ & $2,800-6,000$ & $2,700-3,200$ & $15,000-25,000$ \\
\hline LRT & $300-500^{(6)}$ & $6,000-10,000$ & $3,500-4,500$ & $20,000-30,000$ \\
\hline $\begin{array}{ll}1 & \mathrm{Fo} \\
& \mathrm{pa} \\
2 & \mathrm{H} \\
3 & \mathrm{Fo} \\
4 & \mathrm{Ra} \\
5 & \mathrm{Vc} \\
6 & \mathrm{Vc}\end{array}$ & $\begin{array}{l}\text { ubber-tyred syst } \\
\text { ngers } / \mathrm{m}^{2} \text {. } \\
\text { thesis a frequenc } \\
\text { abber-tyred vehic } \\
\text { e of values depen } \\
\text { es depend on the } \\
\text { es depend on the }\end{array}$ & $\begin{array}{l}\text { s the calculation } \\
\text { f } 3 \text { minutes. } \\
\text { the price is referre } \\
\text { g on the final com } \\
\text { gth of the vehicle. } \\
\text { gth of the vehicle. }\end{array}$ & $\begin{array}{l}6 \text { passengers } / \mathrm{m} 2 \\
\text { a classic traction } \\
\text { ition of the bus. } \\
\text { ues for a length o } \\
\text { ues for a length o }\end{array}$ & $\begin{array}{l}\text { for rail systems } 4 \\
\text { ystem. } \\
\text { ipprox. } 24-46 \mathrm{~m} \text {. } \\
\text { pprox. } 70-95 \mathrm{~m} \text {. }\end{array}$ \\
\hline
\end{tabular}

systems are suggested, which are much cheaper and capable of bring local public transport to ground level with important redevelopment of the urban area.

As can be seen from the table, the transport capacity increase corresponds to an increase in costs connected to the construction of infrastructures. The tram system has a decisive increase in costs because of the installation of the electric substations and the power transmission line as well as the higher costs of the vehicle itself, this does not present any variation in the transport capacity compared to the use of an equivalent bus. It is clear that the tram is competitive based on the following factors: no damaging emissions at a local level, reduced acoustic pollution, lower costs in electricity (which can be produced from renewable resources), average life-span of the vehicles is almost double compared to a bus.

From the analysis of the table other significant elements emerge: traditional rubber-tyred systems are not made to cover a demand for transport of over 4,000 passengers per direction. For lower values of transport capacity, a transport axis run with 18-24 metre-long rubber-tyred vehicles are highly competitive for the lower and more contained infrastructure investments needed. What is also important not to overlook is the fact that an efficient public transport system is usually associated with an increase in demand: for this reason, as has often happened, a rubber-tyred system could quickly reach saturation point and an increase in capacity could be difficult if not impossible. 
Keeping in mind this possible increase in demand can allow for the use of BRT (Bus Rapid Transit), featuring 18 or 24 metre-long rubber-tyred vehicles along equipped axes. The BRT service, which in Europe has not yet become common like in South America and the Far East, has reached maximum use in Bogota in Colombia and Curitiba in Brazil. In Curitiba the vehicles have been organised so as to travel at a speed ranging between 20 and $32 \mathrm{~km} / \mathrm{h}$ (for express services), and with these standards, the rubber-tyred vehicle is a true alternative to a rail system (tram or underground).

The values in Table 1 have been determined by hypothesising, for all systems, an equal frequency of 3 minutes. This value, which is normal for tram systems, is the maximum limit for rubber-tyred systems. Re-editing Table 1 in function of the type of site and the tolerable frequency, the values of Table 2 are obtained, in which there is an evident increase in the gap between the different systems, also according to the choices made by the Public Administration.

Table 2: $\quad$ Transport capacity by tolerable frequency.

\begin{tabular}{|c|c|c|c|}
\hline Vehicle or System & $\begin{array}{l}\text { Single vehicle } \\
\text { capacity } \\
\text { [pass] }\end{array}$ & $\begin{array}{c}\text { Transport } \\
\text { capacity } \\
\text { [pass h dir.] }\end{array}$ & $\begin{array}{c}\text { Frequenc } \\
y \text { [min] }\end{array}$ \\
\hline \multicolumn{4}{|c|}{ MIXED $^{(1))}$} \\
\hline Bus/Trolleybus (12 m) & 100 & 1,000 & 6 \\
\hline Bus/Trolleybus (18 m) & 140 & 1,400 & 6 \\
\hline Bus/Trolleybus (24 m) & 1,800 & 1,800 & 6 \\
\hline \multicolumn{4}{|c|}{ RESERVED ${ }^{(2)}$} \\
\hline Bus/Trolleybus (12 m) & 100 & 1,500 & 4 \\
\hline Bus/Trolleybus (18 m) & 140 & 2,100 & 4 \\
\hline Bus/Trolleybus (24 m) & 180 & 2,700 & 4 \\
\hline Traditional tram & $140-300$ & $2,800-6,000$ & 3 \\
\hline LRT/Stadtbahn & $300-500$ & $9,000-15,000$ & 2 \\
\hline \multicolumn{4}{|c|}{$\begin{array}{l}\text { (1) Mixed : meaning that the means of transport is used in traffic } \\
\text { together with private vehicles. } \\
\text { (2) Reserved: referring to a separate lane which is isolated from } \\
\text { those destined to private vehicle traffic, but will have some } \\
\text { interference at least in intersections. }\end{array}$} \\
\hline
\end{tabular}


It cannot be forgotten how a rubber-tyred system, even with a less prestigious quality level, can however function even without particular traffic regulation, while a tram system will have a decisive impact on the area, both for the movement of the sub-services as well as the laying down of the tracks. For these reasons the creation of a tramway can and must represent the chance for urban redevelopment of the affected areas.

Considering the same transport capacity, a rail system will be more comfortable, both for its intrinsic characteristics, as well as the fact that the capacity of the carriage is normally calculated considering 4 passengers per $\mathrm{m}^{2}$ compared to the 6 passengers per $\mathrm{m}^{2}$ of rubber-tyred systems.

If the demand for transport were enough to require the use of an underground system, as far as investments go, the model defined as LRT (Light Rail Transit or Light Rapid Transit), also known as Stadtbahn or surface metro system, would be highly competitive. It is, indeed, a perfect compromise in terms of transport capacity between a classic tram and an underground.

As well as an increased transport capacity and increased flexibility compared to the adjustment to the demand for transport (rail systems are modular, as they can have multiple compositions), the LRT model presents two evident advantages: reduction in the initial investment for the construction of the infrastructure and increased accessibility for the users since it is mostly surface transport.

In general, rail service represents today the only approach able to fully satisfy the increasing demand for transportation both on a regional and metropolitan level. This observation can be proven by looking at the data from Europe over that last 20 years and the phenomenon has become increasingly marked in the last few years, as can be seen in Figure 3.

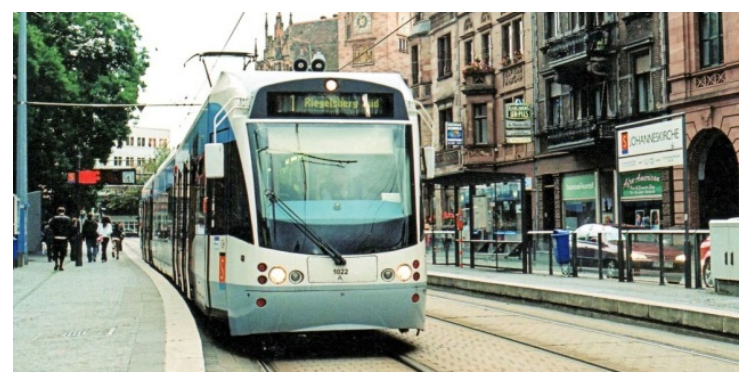

Figure 3: $\quad$ Tram train in Saarbrücken.

\begin{tabular}{|c|c|c|c|c|c|c|c|c|}
\hline \multicolumn{8}{|c|}{ thousand mio pkm } & $\%$ \\
\hline & 1990 & 1995 & 2000 & 2005 & 2006 & 2007 & 2008 & $\begin{array}{l}\text { CAANGE } \\
\text { 107/08 }\end{array}$ \\
\hline EU-27 & & 71.1 & 77.1 & 82.4 & 84.2 & 85.9 & 89.0 & 3.5 \\
\hline EU-15 & 49.0 & 48.8 & 54.7 & 59.9 & 61.6 & 63.2 & 64.7 & 2.4 \\
\hline U-12 & & 22.3 & 22.5 & 22.5 & 22.5 & 22.7 & 24,3 & 6.8 \\
\hline
\end{tabular}

Figure 4: Development of tram and underground railway in Europe. Source: "EU Energy and Transport". 
In conclusion, in the case where the opportunity can be ascertained and the necessary technical conditions are available, it is possible to implement an interoperable system (tram-train) which helps eliminate the transit points connecting systems and rolling stock with relevant scale economies (Karlsruhe model). Karlsruhe S-Bahn was opened in 1992 through the connection between the tramway urban net and the railway lines. On the eleven-line system, $468 \mathrm{~km}$ long, running 115 tram- train: the success of the system allowed for an increase of up to 48 transits per hours per direction in Markplatz and Kriegstraße (including urban tramways), and for this reason, the construction of a "city tunnel" has been planned.

\section{The technology factor in public transport}

In the overview of public transport, both rubber-tyred systems and rail systems have undergone remarkable technological progress in the last few years which has determined the increasing attraction for users. This element also contributes in a significant manner to a push for not using private vehicles in urban and suburban transport.

Initially it intervened to making public transport more useful for all users, including the elderly, women (and men) carrying strollers, persons with reduced mobility, wheelchair users and all those who have to transport cumbersome baggage. This objective was reached by using lowering floors (FLF - Full Low Floor - and ULF vehicles - Ultra Low Floor), which make the entrance to the vehicle at the same level of the pavement, as well as widening the doors. Regarding the latter, there is an increased use, also in rubber-tyred vehicles, of sliding doors over the traditional folding doors.

For electric propulsion systems, with the widespread use of efficient IGBT power actuators capable of controlling three-phase asynchronous motors, the use of instruments for energy saving is perfecting, through the use of supercapacitors to recover the energy used during braking.

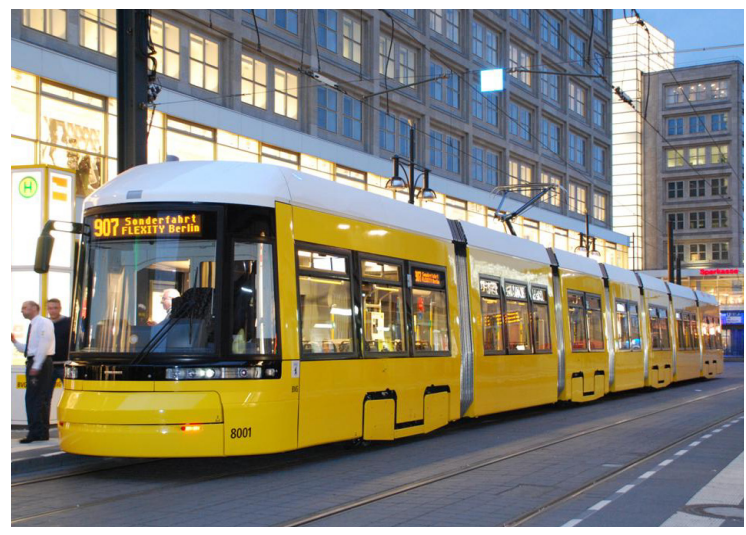

Figure 5: Modern tram in Berlin. 
Concerning the overhead electric lines, an aspect which has posed some concern especially in urban settings with architectural prestige, it is possible to replace the same with the new ground-level power-supply system. Ground power supplies not only eliminate the visual impact of overhead cables, but also allow for the transit of vehicles in tunnels and underpasses which are too low for overhead cables. Currently, the market offers three different solutions for ground power supply:

1. APS: acronym for Alimentation Par le Sol, a conduction system currently operational in Bordeaux;

2. TRAMWAVE: a conduction system currently in experimentation on the urban tram line in Via Poggioreale in Naples;

3. PRIMOVE: an induction system with accumulation in modules and supercaps, in experimentation in Mannheim, suitable for tram systems as well as trolleybus systems as long as they are driver assisted.

In the field of tramways the new technological equipment consists of using prefabricated modules which makes it easier and faster to lay down the tracks helping to reduce construction time. With the use of viscoelastic materials between the road surface and the track, and the insertion of elevated connections in curves, together with the use of new pivoting cars, excellent comfort levels can be obtained for travellers as well as the near-complete elimination of noise pollution.

The internal areas of the vehicles, which have also been the object of design studies, are now using seats without struts and made in non-toxic materials (even in case of fire) and the use of washable fabrics resistant to vandalism.

\section{New models for public transport in urban areas}

The creation of main rail lines in the urban area has historically seen the development of the classic underground systems (like the extensive networks in Paris and London) whose only variations are represented by portions of the line, even extensive ones, on embankments. At the same time, but with less use, have been the "metropolitan railways", dedicated axes with specialised rolling stock like the S-Bahn in Berlin or in Vienna (which has been reconverted and incorporated in the underground network as line U6).

The union of innovation and technology and the willingness to overcome some historical prejudices regarding different systems (using the train for midlong trips, the underground for mass movement in urban areas with stations close to each other, tram for short distances in urban areas), have allowed the development of new solutions, which in most cases have led to the enhancement of existing networks. Today we are seeing, for the reasons mentioned above, the reinsertion of rail use inside urban centres keeping them on the surface. There are two models used to pursue these objectives: 
- $\quad$ evolution of tramways on protected axes (LRT or Stadtbahn);

- re-planning of regional services integrating railway and urban networks (tram-train).

In this context it is therefore possible to identify a further plan for interoperability represented by the union of classic tramways with LRT systems, as is the case in Alicante: but what is still missing is the integration between tram-train systems and LRT which would represent the link between all the systems. This notwithstanding, even traditional models, based on the development of previously existing urban networks (tramways, undergrounds and city rail links), optimising and strengthening the interchanges offer clients a high level, efficient service. An example is the city of Zurich, main commercial and industrial centre of Switzerland and capital, it has a population of approximately 450,000 inhabitants to which must be added the number of workers residing outside the city, and visitors for business or pleasure. The Canton has an extension of $1,729 \mathrm{~km}^{2}$ and a population of approximately $1,300,000$ units distributed in centres of different natures (mountainous or flat areas) and sizes. The ZVV (Zürcher Verkehrsverbund) took over all the strategic decisions regarding public local transport and the coordination of activities of the different entities involved in the mobility industry in their relative areas. The integration of the fare allows the use of all services, including long-distance trains, and in particular those in the first city rail link, active since 27 May 1990, which transports over 400,000 passengers a day. A second city rail link of 4.8 $\mathrm{km}$ is currently under construction to directly connect the station of Altstetten to Oerlikon and which has planned the creation of a new underground station, Löwenstrasse (immediately under the main station).

The strengthening of the surface tramway and the development of city rail transport to the expense of the underground, was sanctioned by a referendum in 1960, which represented the starting point for the development of the S-Bahn system, perfectly integrated with the tram network (13 lines and 208 trolleys and 35 tram trailers ) and the trolleybus system (6 lines and 78 trolleys, 17 of which are 24-metre long). Bordeaux, a French city with over 230,000 inhabitants which go over the amount of 1,200,000 when the entire metropolitan area is taken into consideration, has seen, over the last ten years, the development of a modern surface transport network. The local authority is the Communauté Urbaine de Bordeaux, whose job is to define the collective transport policy within its territory, including an integrated tariff system. Through the transit authority, TBC (Tram et Bus de la Communauté Urbaine de Bordeaux), which has given the operation of the tram and bus network, from 2009 to 2014, to the company Keolis Bordeaux, a branch of the Keolis Group, the management focuses on automobile services as well (among which 14 high-capacity express lines - "Les Lianes"), a tram network which took over in the plans at the end of the $90 \mathrm{~s}$ in alternative to the automated underground (VAL - Véhicule Automatique Léger). For the service used daily by approximately 165,000 users are the three lines (A, B and C) with a total extension of $47.7 \mathrm{~km}$, on which are used 84 trams with APS ground power supply. Particular attention was paid to the connections of the historical centre to the industrial, university and residential areas with the SNCF 
(Société Nationale des Chemins de fer Français) rail system, requiring further investments amounting to 285.3 million $€$ for the extension of lines A, B and C for a total of $13.9 \mathrm{~km}$ and 47.4 million $€$ for the first stretch of $1.8 \mathrm{~km}$ of the new line D. Also, 70 million $€$ have been set aside for the creation of the tram-train system "Tramway du Médoc" integrated at all levels with the urban network which determines the creation of $7.2 \mathrm{~km}$ of new tracks.

Stuttgart, capital of the federal state of Baden-Württemberg, constitutes the most interesting model of city LRT obtained from the progressive and total reconversion (a process which lasted 30 years) of the tram network with metric gauge tracks. The $1435 \mathrm{~mm}$ standard gauge city Stadtbahn managed by SSB (Stuttgarter Straßenbahnen AG), together with the regional S-Bahn operated by DB (Deutsche Bahn AG) and the conventional train tracks (6 lines S1 - S6 with an extension of $177 \mathrm{~km}$ ), serves the 600,000 residents of the city and the 2.6 million people resident in the "greater Stuttgart area" which is also centred around the city, because of its high levels of work and school commuters.

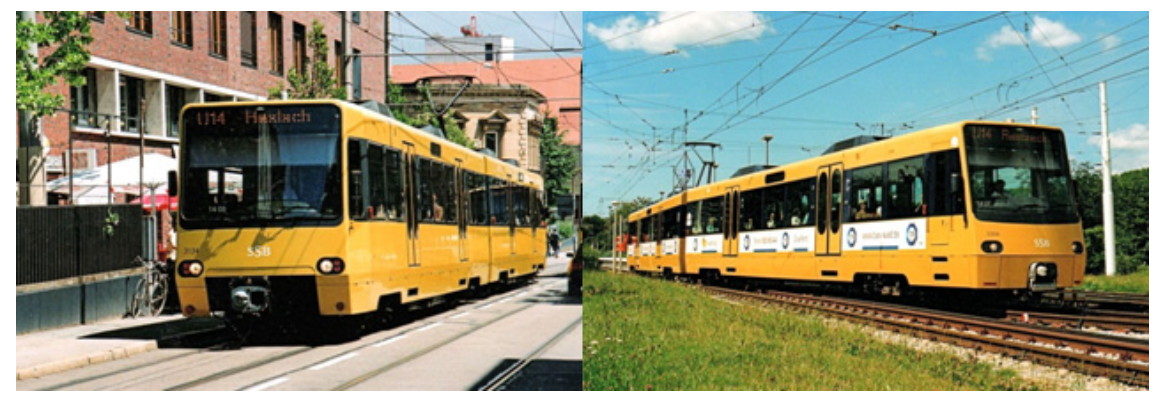

Figure 6: Stuttgart Stadtbahn.

These movements represent over two thirds of the trips made in the integrated tariff system with an increase in users notwithstanding the economic downturn. The Stadtbahn of Stuttgart is made up of 15 rapid lines, both in tunnels and on the surface in dedicated areas, articulated over a length of $128 \mathrm{~km}$ and extending to different areas of the city and the hinterland. The service is implemented through 164 articulated vehicles and three single car trams working the metric gauge line 10 and a gauge line $2.2 \mathrm{~km}$ long. A peculiarity of the Stadtbahn in Stuttgart is the possibility of the vehicles in service to use parts of the line together with urban traffic and to allow boarding both from raised platforms $(900 \mathrm{~mm})$ and normal sidewalks through retractable stairs.

\section{Conclusions}

In this paper it has been highlighted as some of the leading European cases in public transport, have made choices, in consideration of local needs such as the conformation of the territory, and the size of the population and the commuting.

It is clear that a technology cannot be defined in absolute terms "better" than another, but it is necessary to define the technology as "appropriate". In fact the adaptation to local needs can produce added value for the territory as in the case 
of the choice of transport model LRT systems or wire-free. In fact, the decision process for the planning of new public transport systems, derives from a number of implications for the city, in terms of demand for transport, urban development and environment.

In order to reduce the transit points, public administration and industries' attention should be aimed at the use of tram-train systems and LRT. In general the current trend is to transfer the main flows of passengers onto rail axes (guide rail), which permit the use of long trains (for example tram line 6 in Budapest works with $54 \mathrm{~m}$ long vehicles); the increased complexity of infrastructure becomes a pillar for urban re-qualification and re-organization processes aimed at the environmental sustainability of our cities.

Moreover a transport policy designed to foster modal shift should be considered: first priority should be given to public transport instead of private transport, all in the interests of greater efficiency and sustainability. It is not accident that, in cities with a high percentage of public transport and the habit of walking and cycling, the cost of transportation for the community, expressed as a percentage of the urban GDP is half that of cities where the percentage of public transport is low.

As described, the right balance between choice of technology and transport policy allows a safe, sustainable and affordable mobility. Investing in sustainable and efficient transport networks will help stabilize the world energy market, mitigate the role of transport in climate change, support economic growth and quality of life in cities and relieve the congestion of mobility. Public transport is means progress for society.

\section{References}

[1] C. Carnevali, G. Garbarini, R. Genova, M. Mazzucchelli, A. Sasso Fast inductive recharge for public transport on medium dimensions electric buses. The first experience in Genoa, Urban Transport, 19-21 May 2004, Dresda (Germany).

[2] I costi sociali e ambientali della mobilità in Italia Amici della Terra, Ferrovie dello Stato Quinto rapporto, October 2005.

[3] M. Maibach, C. Schreyer, D. Sutter H.P. van Essen, B.H. Boon, R. Smokers, A. Schroten, C. Doll, B. Pawlowska, M. Bak, Handbook on estimation of external costs in the transport sector, Report, Delft, February, 2008.

[4] European Commission, EU energy and transport in figures, Statistical pocketbook 2010.

[5] F. Ballini, R. Bozzo, C. Carnevali, R. Genova, A comparison of methods in planning urban transport networks, considering new perspectives in interoperable system, Proceedings of "2011 IEEE Forum on Integrated and Sustainable Transportation Systems", June 29-July 1, 2011, Reed Messe Wien, Vienna (Austria).

[6] R. Bozzo, C. Carnevali, R. Genova, G. Priano, Ruolo, prospettive ed innovazione tecnologica per i sistemi su gomma ad elevata capacità di trasporto, Primo Convegno Sistemi Gomma, ASSTRA Rome (Italy), 23 24 November 2011. 